\title{
Unexo: 0 método de design automotivo aplicado ao desenvolvimento de maquinário agrícola
}

\section{Unexo: The automotive design method applied to the development of agricultural machinery}

MOHR JUNIOR, Klaus Dieter

Fundação Universidade Regional de Blumenau - FURB I kdmjunior@gmail.com

SANTOS, Marko Alexandre Lisboa dos

Fundação Universidade Regional de Blumenau - FURB I kakosantos@gmail.com

CRUZ, Alexia Luanda Teske da

Fundação Universidade Regional de Blumenau - FURB I alexiadacruz@gmail.com

\begin{abstract}
Resumo
Este artigo apresenta o processo de desenvolvimento de um Projeto Automotivo com foco em um maquinário agrícola conceitual e relata a experiência adquirida assim como as dificuldades encontradas. Essa incursão se utilizou de um método de projeto específico do Design e da Engenharia de Produto que vai dos desenhos manuais e digitais até a representação por meio de um modelo tridimensional em escala - um mockup.
\end{abstract}

Palavras-chave: Design automotivo. Maquinário Agrícola. Sketch Automotivo. Impressão 3D.

\section{Abstract}

This paper presents the development of an automotive design project focused on conceptual agricultural machinery, and reports on the experience and difficulties faced along the process. This venture used a specific method applied in the fields of Design and Product Engineering, which ranges from manual and digital drawings to realistic representation by means of a three-dimensional scale model - a mockup.

Keywords: Automotive design. Agricultural machinery. Automotive sketch. 3D printing. 


\section{INTRODUC̣ÃO}

O designer automotivo é o profissional responsável por desenvolver as formas, as funções, a estética e até a aerodinâmica dos mais diversos meios de transporte. Em países europeus e nos Estados Unidos da América existe uma vasta quantidade de universidades com cursos específicos para o design de transporte, ou automotivo, onde as aulas são ministradas, em sua maioria, por profissionais da indústria. No entanto, o Brasil não conta com nenhuma universidade com um curso de Design específico desta área. Embora existam cursos com tradição na formação de estudantes que possuam essa vocação e alguns cursos sequenciais, pode-se admitir que a formação acadêmica nessa área é ainda insipiente. Com a escassez desses cursos, a quantidade de materiais didáticos brasileiros sobre esse tema também é exígua.

O processo do design automotivo é um pouco diferente de um projeto de design de produto convencional devido ao seu alto grau de complexidade e investimento necessário para um resultado satisfatório. É por isso que se justifica a escrita deste texto relatando tal processo.

Neste sentido, este artigo tem a finalidade de apresentar o processo de desenvolvimento de um Projeto Automotivo, demonstrando o método projetual assim como relatando os desafios percorridos no contexto de um Trabalho de Conclusão de Curso em uma Universidade de Blumenau/SC. Para tanto, foi realizada uma pesquisa bibliográfica para dar a devida sustentação necessária ao projeto de modo que a partir dos dados extraídos da mesma, a concepção foi iniciada.

\section{O MÉTODO DE PROJETO}

Para este projeto foi utilizada uma mescla de três metodologias: a de Baxter (2001), a de Munari (1997) e de Chase, Jacobs e Aquilano (2006). Ressalta-se que as duas primeiras são especificas para projetos na área de Design, já a de Chase, Jacobs e Aquilano (2006), apesar de não se tratar de um método especifico para área de Design, se mostrou pertinente para este trabalho. A união das metodologias resultou nas seguintes etapas de desenvolvimento: identificação de oportunidade, formulação de objetivos, análise de mercado, criatividade, materiais e técnicas, seleção da alternativa, projeto de fabricação e confecção do modelo.

Para a obtenção de referencial teórico e imagético, foram utilizados livros e pesquisa em sites de montadoras e bancos de imagens. Além disso, foram realizados estudos sobre novos materiais em desenvolvimento por laboratórios de universidades como Stanford, Harvard, MIT, e demais instituições. Destacase aqui também a utilização das redes sociais para a obtenção de informação, já 
que muitos designers possuem perfis nessas redes onde disponibilizam dicas, tutoriais e assuntos de interesse para estudantes de design.

\section{IDENTIFICAC̣ÃO DE OPORTUNIDADE}

Sabe-se que é do campo que vem a maior parte dos alimentos que sustentam a população mundial e para o aumento da produtividade é fundamental a aplicação, de maneira correta, da mecanização. As máquinas diminuem o trabalho humano árduo, possibilitam o aumento da área de cultivo e potencializa o rendimento, reduzindo a necessidade de uma excessiva mão de obra humana (YAMASHITA, 2010).

A cada ano verifica-se o aumento da população mundial, consequentemente, devido ao crescimento da quantidade de pessoas no planeta, eleva-se a demanda por alimentos. No entanto, de acordo com a FAO (FOOD AND AGRICULTURE ORGANIZATION OF THE UNITED NATIONS, 2013), apenas cerca de um bilhão e trezentos milhões de pessoas - metade da população ativa do mundo - são trabalhadores rurais. Atualmente, o planeta conta com aproximadamente vinte e oito milhões de tratores, algo em torno de dois por cento do número de ativos agrícolas.

Sob um olhar crítico, sobretudo no que se refere à forma, à função e a questões ergonômicas, procuraram-se oportunidades de melhorias observando os diversos maquinários agrícolas. Sendo assim, no que se referem às suas formas, identificou-se que sua aparência primordial é dada, sobretudo, por superfícies de cobertura de peças mecânicas, como para-lamas, capô, teto, entre outros elementos. Tais superfícies, pouco se preocupam com questões formais e estéticas de modo que são desenhadas, maiormente, a partir de linhas retilíneas e formas poligonais, que se unem por meio de ângulos agudos.

Correspondente aos demais elementos do veículo, como bancos, volante, painel, alavancas, botões e demais componentes a serem manuseados por algum ser humano, são desenvolvidos sob uma ótica completamente funcional e pouco ergonômica, em sua maioria.

Em outras palavras, observou-se que, de um modo geral, estes maquinários não apresentam aspectos básicos do desenvolvimento da forma em Design, como: Unidade, Conceito, Linguagem, Ergonomia, entre outros (GOMES FILHO, 2006; LOBACH, 2001).

Para fundamentar e melhor compreender o cenário em que este projeto está inserido, foi realizada uma pesquisa no segmento agrícola, materiais e processos de fabricação emergentes, além de uma pesquisa de mercado; esta última para identificar os produtos similares existentes. Neste sentido, foi 
MOHR JUNIOR, Klaus Dieter; et al.

necessário aprofundar as discussões a partir do tema central do trabalhado, ou seja, as questões que envolvem o plantio agrícola.

\section{ANÁLISE DE MERCADO}

Foi realizada uma pesquisa de mercado para identificar as marcas e os modelos existentes de tratores em geral. Foram analisadas algumas características presentes nos veículos com o intuito de identificar possíveis segmentos e oportunidades em um mercado já existente.

Figura 1 - Análise de similares.

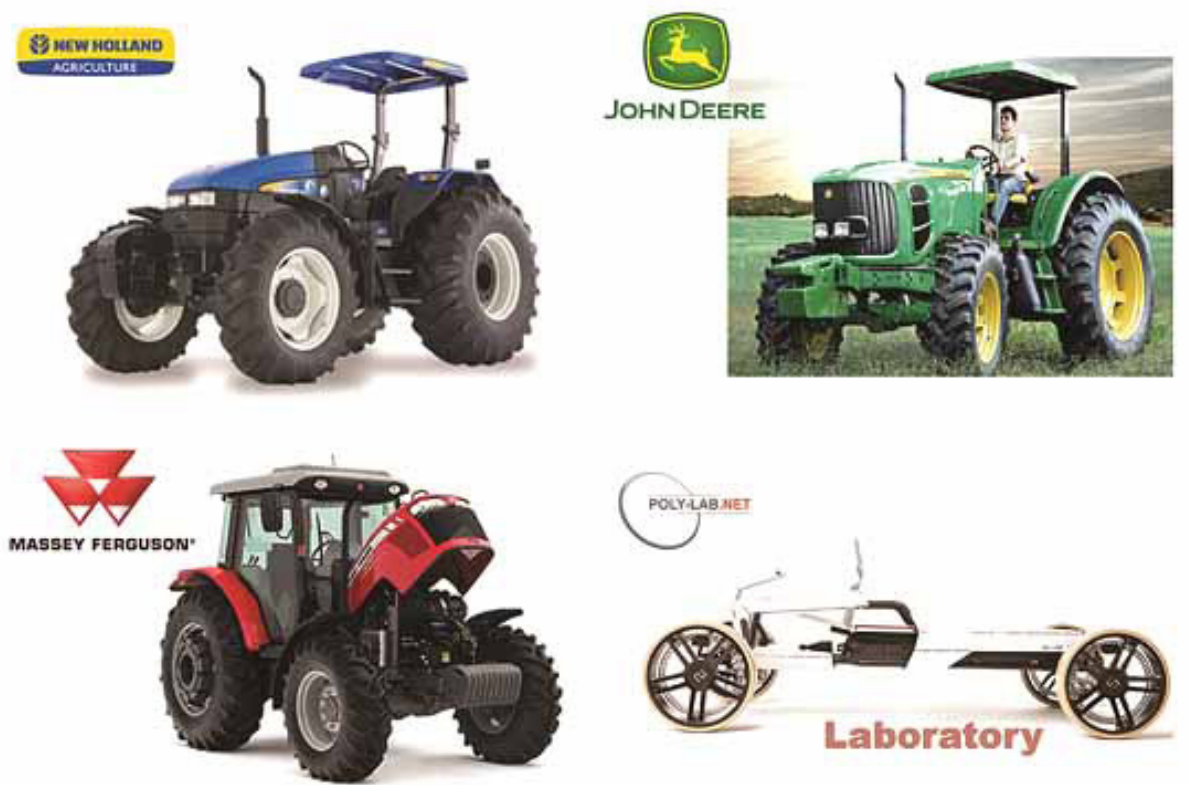

Fonte: Montagem própria a partir de imagens do site das montadoras.

\section{MATERIAIS E TÉCNICAS}

Os materiais utilizados determinam os processos de fabricação e por muitas vezes, ambos ditam a aparência do produto. Gradualmente, o constante investimento no processo de manufatura rápida - popularmente conhecido como impressão 3D - faz com que se abram outras possibilidades para o designer apostar em novas formas com resultados cada vez mais rápidos e menos onerosos.

Entre as diversas vantagens oferecidas pela impressão 3D, merece destaque o aspecto ambiental e financeiro, uma vez que este sistema utiliza apenas a quantidade necessária de material para a confecção da peça, diferente dos métodos convencionais que acabam descartando excedentes de matéria prima, seja na estampa ou na junção de duas peças pelo processo de soldagem, usinagem, colagem, entre outros. 
Pelo fato dos materiais e processos de manufatura influenciarem no estilo, ou design dos veículos, os maquinários automotores utilizados na agricultura acabam por ser muito semelhantes. Basicamente a estrutura de tais implementos agrícolas se dá pela junção de dois volumes independentes, sendo um deles destinados à cabine de direção, tendo o operador sentado praticamente sobre o eixo traseiro.

Contudo, é possível encontrar uma alternativa eficiente para o trabalho no campo. Os Unimogs são caminhões de característica off-road multifuncionais, nestes veículos a posição de operação situa-se na frente do veículo, em cima do eixo dianteiro. O termo Unimog remete-se ao alemão UNiversal MOtor Gerät, e teve a sua utilização na agricultura iniciada logo após o fim da Segunda Guerra Mundial. Este veículo possui todas as características de um trator com alguns aspectos adicionais, como a suspensão, por exemplo, que possibilita maior conforto e segurança em velocidades elevadas. Hoje ele é produzido pela Mercedes-Benz e pode ter acoplado mais de mil implementos, o que o torna em um dos mais versáteis veículos de produção seriada dos dias atuais.

A partir dos dados levantados em sites de fornecedores de tecnologia, foram definidos alguns materiais que seriam utilizados para fabricação do produto real. Desse modo, para a carroceria, seria empregado um polímero reforçado com fibra de carbono, construído a partir de técnicas de prototipagem rápida - impressão 3D. Como unidade motriz, seriam utilizados motores elétricos in-wheel, que se encaixam no centro de cada roda. No sistema elétrico, como material condutor, seria utilizado o estaneno - do inglês stanene -, que se trata de um material supercondutor, ainda em estudo pela Universidade Stanford, que de acordo com os estudos teóricos realizados possivelmente será um material apto a transmitir dados e energia sem a perda de ambos, por não apresentar alta resistência em temperatura ambiente. Com isso ocorreria um aumento do desempenho das baterias, que hoje é o principal contratempo em veículos elétricos.

\section{PROCESSO CRIATIVO E ESCOLHA DE ALTERNATIVAS}

O conceito do veículo foi constituído por meio de três aspectos. O primeiro é o local de trabalho do automóvel: o campo e a natureza. Dessa temática, chegou-se à sequência de Fibonacci e consequentemente à espiral áurea. O segundo aspecto relevante é a linguagem de superfícies orgânicas e fluídas que vem sendo explorada pela Mercedes-Benz, tendo em vista de que o projeto é uma sugestão para uma futura versão do Unimog. O terceiro aspecto destaca os dez princípios do "bom design", cunhados por Dieter Rams, sobretudo pelo seguinte: o bom design deve conter o menos design possível. Para reunir as formas e inspirações, foi montado um painel visual com as imagens de referência, observe na Figura 2: 
Figura 2 - Painel Visual.

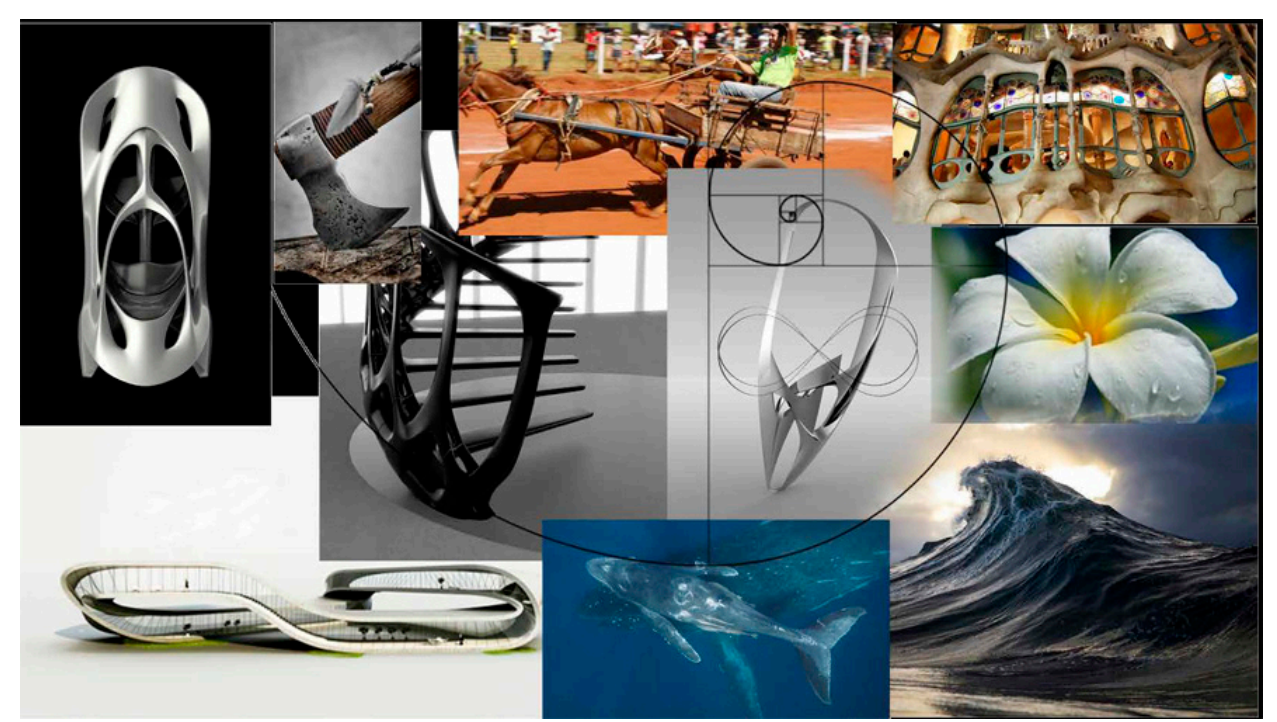

Fonte: Autoria própria.

A etapa da geração de alternativas é a fase em que o veículo começa a ganhar forma, cor, textura, e demais elementos da linguagem visual (LUPTON; PHILLIPS, 2008). Para a geração de alternativas do projeto foi utilizada uma mescla de técnicas, manuais e digitais. Salienta-se aqui que a técnica 2D continuamente se relaciona à $3 D$, isto é, ela é utilizada ininterruptamente até o fim do projeto, tendo em vista de que o processo de desenho manual é a forma mais rápida de se transmitir a ideia e o processo tridimensional é um método mais rápido de se avaliar o resultado.

A alternativa selecionada para o chassi foi a que mais se encaixou à proposta, levando em consideração a harmonia, fluidez e a transição orgânica entre as superfícies, conforme evidenciado na Figura 03. Após isso, o próximo passo se deu com a adequação do dimensionamento do chassi.

Figura 3 - Geração de alternativas do chassi.

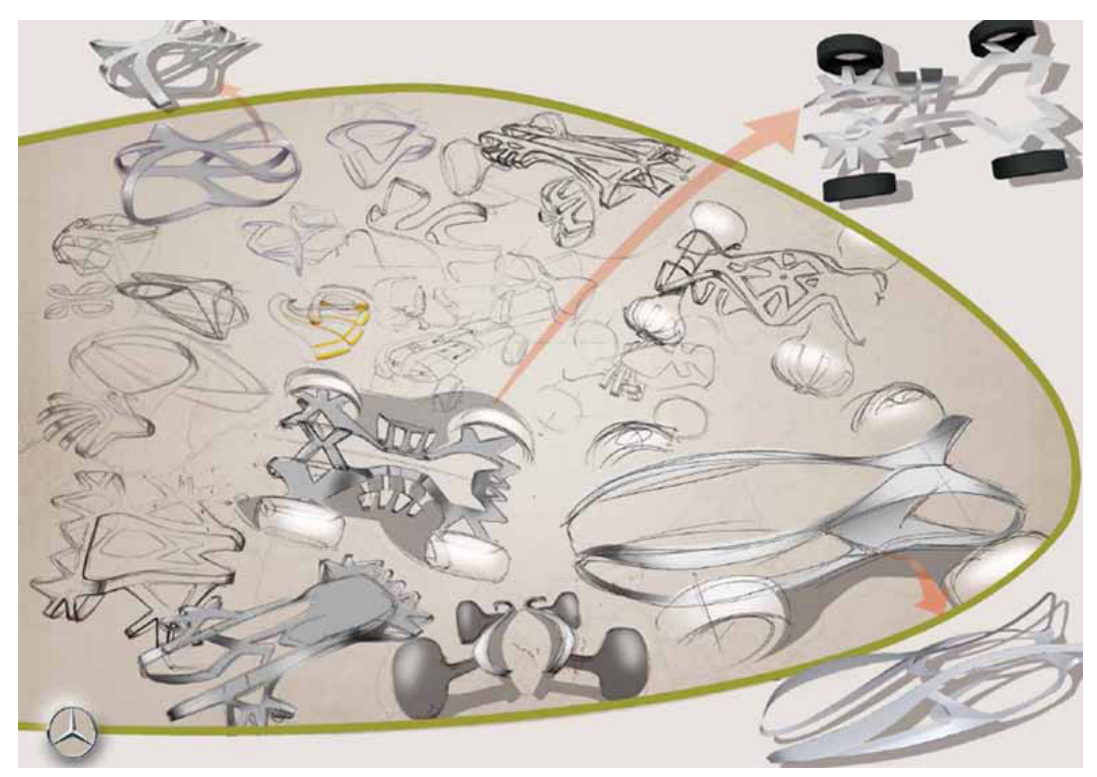

Fonte: Autoria própria. 
Uma vez que todo o projeto deveria seguir a mesma linguagem, iniciou-se o desenho dos demais componentes. Foram concebidas alternativas de "santantônio", volante, rodas e bancos, por meio de sketches manuais que posteriormente foram modelados tridimensionalmente para avaliação. Este processo ocorreu até que a melhor solução estética e funcional fosse identificada.

Na geração de alternativas para a roda, foi levado em consideração que este componente deveria corroborar com a linguagem do veículo como um todo, ou seja, ela não seria um elemento "à parte", que destoasse do conjunto restante. Por esse motivo, a alternativa escolhida foi aquela inspirada pela flor copo-de-leite, transformando roda e pneu em um único elemento, observe na figura 4:

Figura 4 - Geração de Alternativas da roda.

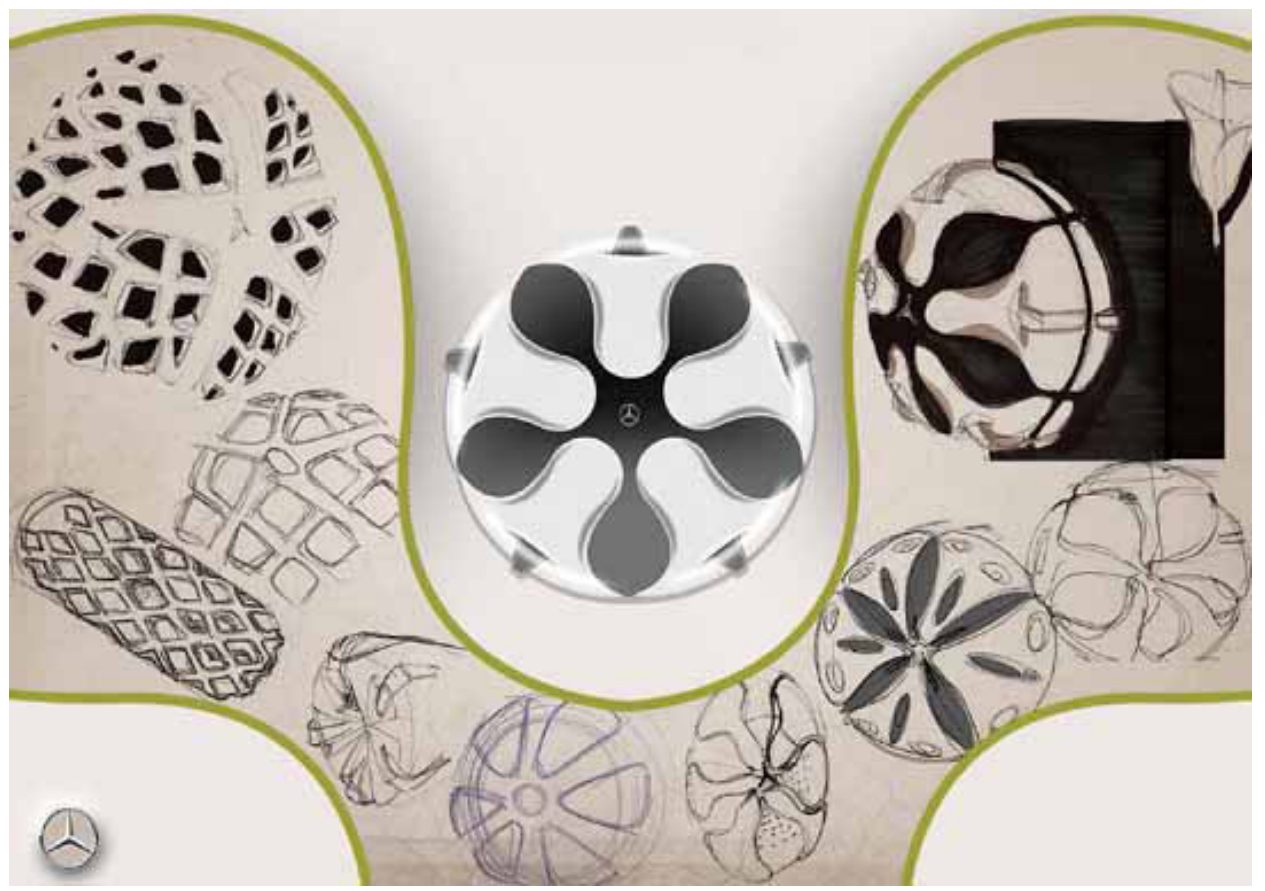

Fonte: Autoria própria.

As alternativas do volante tiveram início a partir da prerrogativa que o mesmo fugisse dos modelos convencionais. Por que os volantes dos automóveis são sempre circulares? Os veículos agrícolas mais simples são movidos à tração animal e o elemento utilizado para mudar a direção são as rédeas. Tomando estas últimas como inspiração, foram geradas diversas alternativas de volante. A alternativa escolhida foi a opção evidenciada na figura 05, com as superfícies transpassadas entre si, lembrando a aparência de uma rédea. 
Figura 5 - Geração de Alternativas do volante.

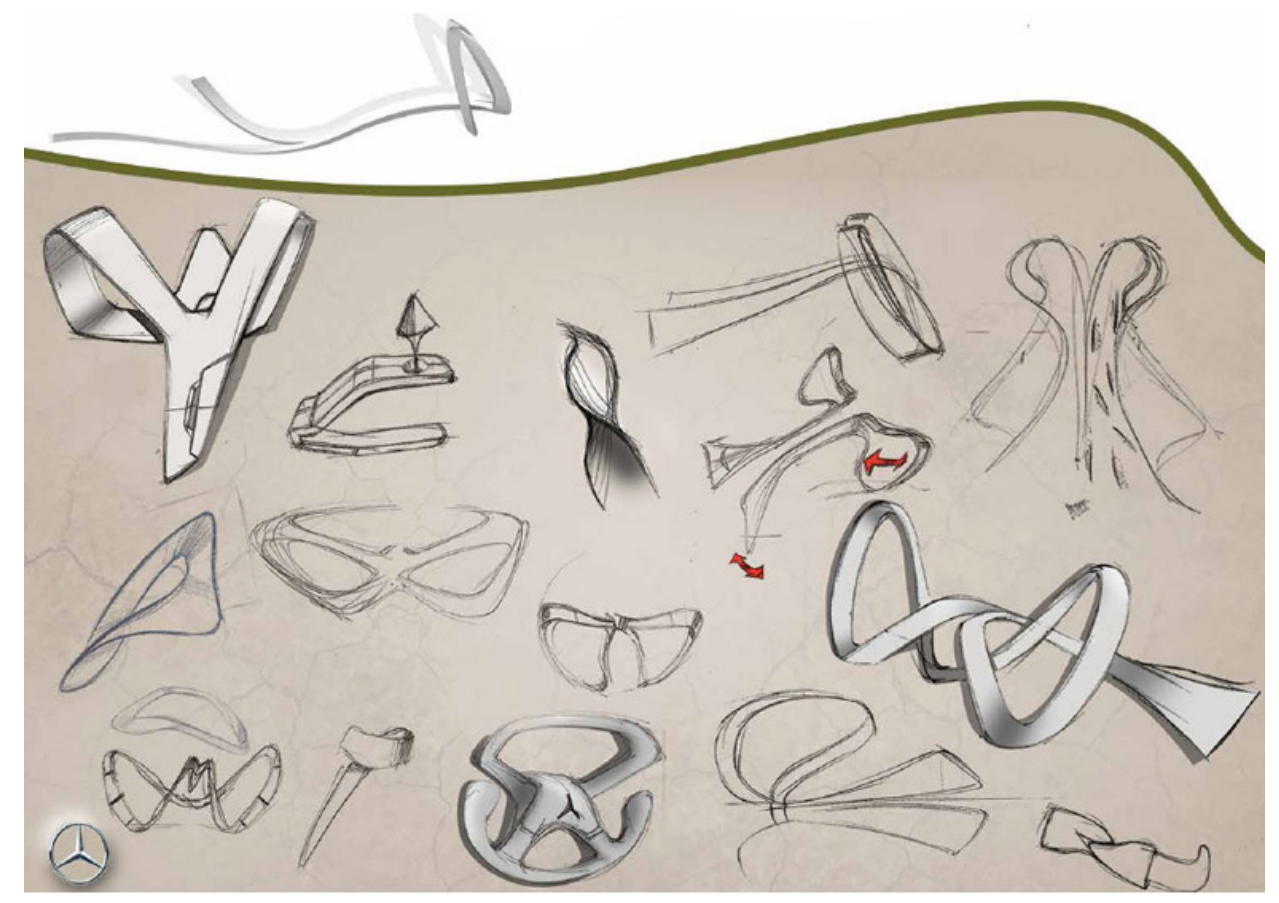

Fonte: Autoria própria.

A estrutura da cabine, composta pelo "santantônio", advém da forma das ondas do mar e faz uma continuação tangenciando as superfícies do chassi, fazendo com que toda a estrutura seja uma única peça.

Figura 6 - Geração de alternativas da cabine.

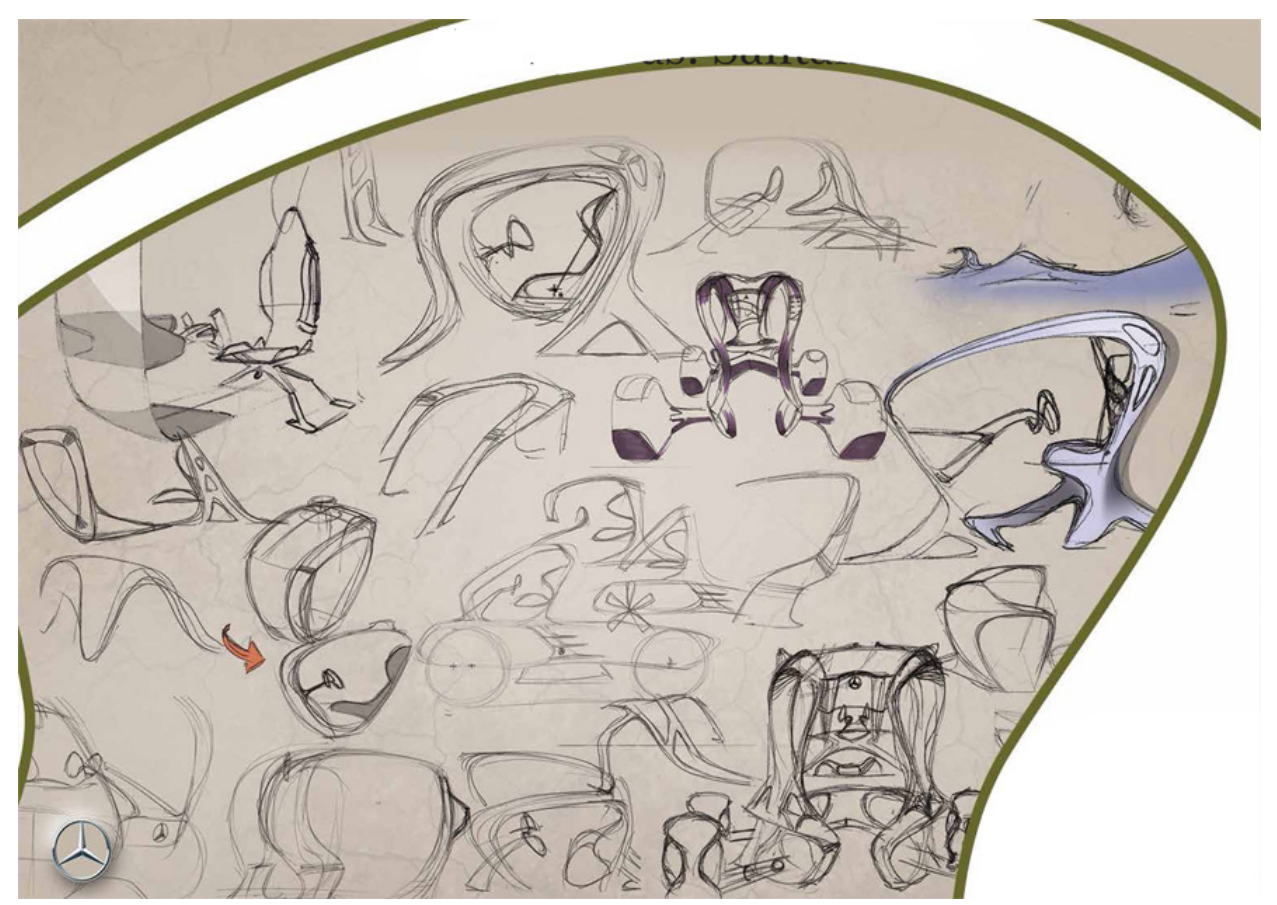

Fonte: Autoria própria.

Juntamente ao processo da criação da cabine, foram concebidos os para-lamas, que se encontram no ponto onde a estrutura da cabine se junta a do chassi. No caso do para-lama não foram desenvolvidos sketches, sendo estes gerados diretamente no software Autodesk Alias. 
A última fase de geração de alternativas foi para o banco. A alternativa escolhida tem a sua forma baseada na germinação de uma semente, o que resultou em uma forma que sai completamente do estilo convencional devido a sua aparência assimétrica, conforme a figura 7.

Figura 7 - Geração de alternativas do banco.

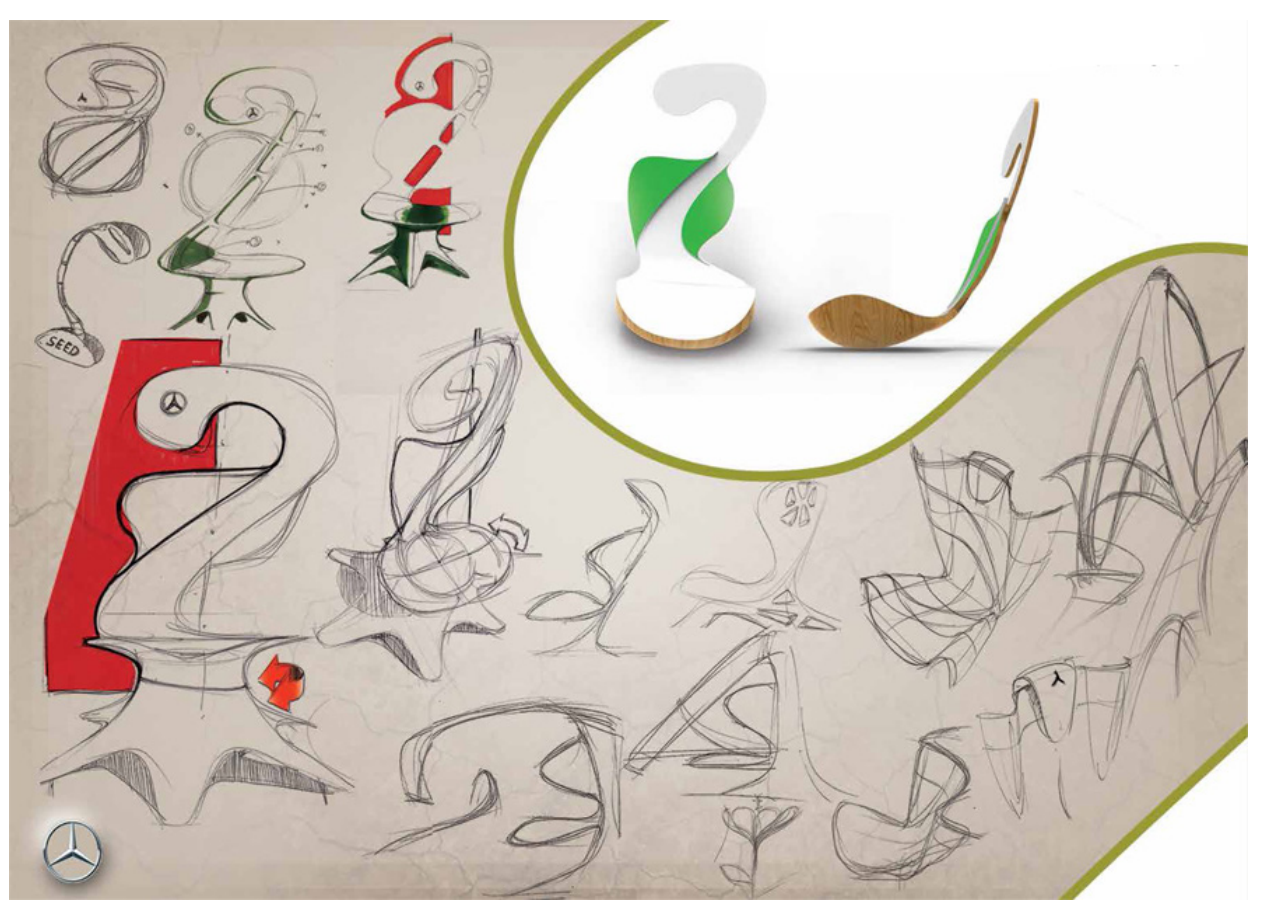

Fonte: Autoria própria.

Com as demais partes prontas, os últimos componentes a serem concebidos foram as lanternas. Utilizando a espiral áurea como canvas - base - determinou-se que esses componentes deveriam seguir a mesma linguagem utilizada nas demais partes até então desenvolvidas.

Com a intenção de detalhar mais o mockup e o rendering digital, foram construídas algumas peças para simular a parte mecânica do veículo. Nesse sentido foram modelados dois volumes que representariam a unidade motriz além de um volume para representar um encaixe de guincho na frente, este último foi projetado apenas para o rendering.

Após a conclusão das alternativas das peças, foi realizado um rápido brainstorming - técnica de desenvolvimento da criatividade (BAXTER, 2001) para a criação do nome do projeto. Com a junção das palavras Unendliche, do alemão "infinito" - retirado da obra de Max Bill "Unendliche Schleife" -, e exo, do grego "fora" - retirado da palavra exoesqueleto -, formou-se o nome do veículo: UNEXO. 


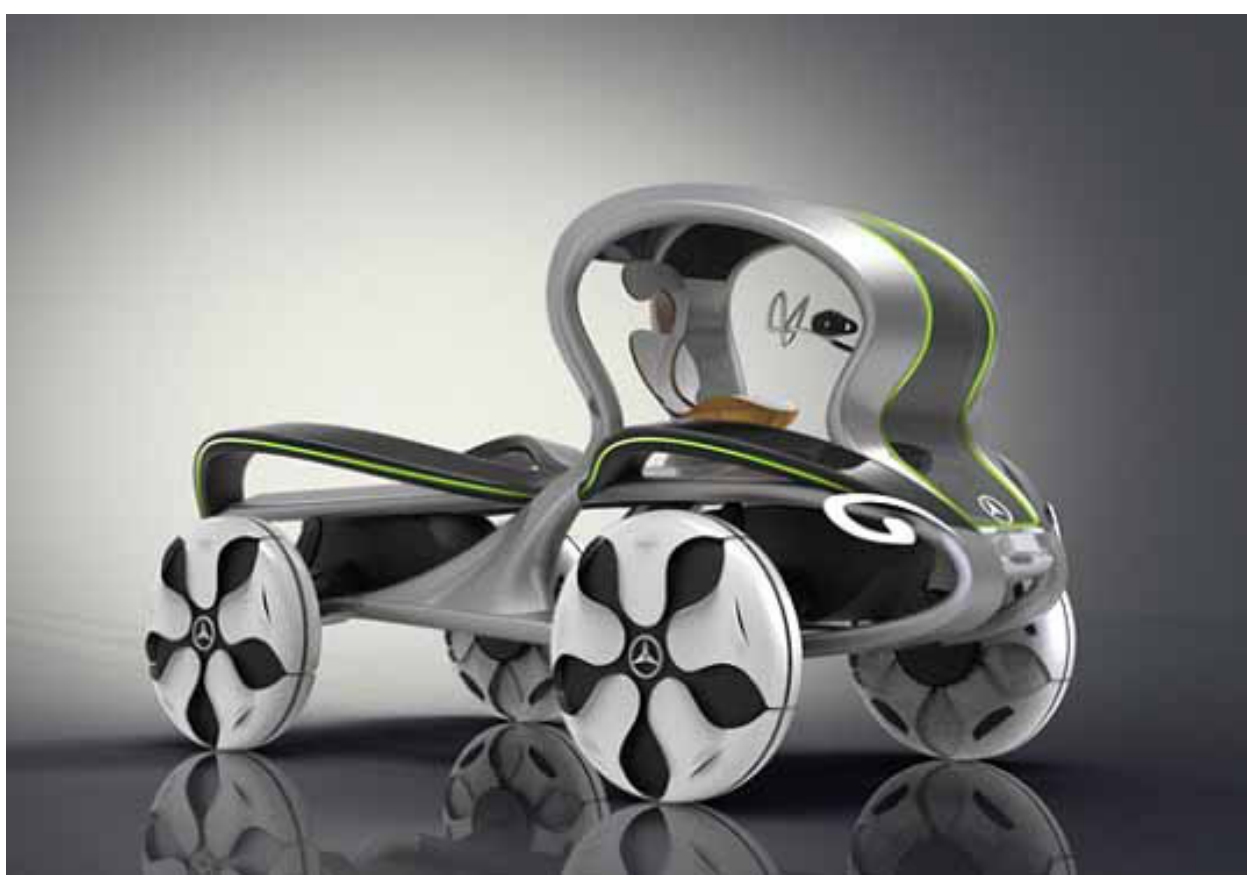

Fonte: Autoria própria.

\section{CONFECC̣ÃO DO MOCKUP}

O mockup foi construído em uma escala de redução de 1/14 da dimensão real, para tanto, foram utilizados materiais alternativos para a confecção e acabamento do mesmo. A impressora na qual as peças foram impressas utiliza um filamento de plástico ABS para gerar os volumes do UNEXO. Já para o acabamento e montagem foram utilizados os seguintes materiais: massa plástica, cola epóxi, lixas (granulações de 120, 600 e 1200), tinta automotiva, retífica para acabamento e seladora de plástico.

Foram gerados arquivos STL - Stereolitography - para a impressão do modelo. O modelo matemático e a espessura para a impressão foram construídos no software Autodesk Alias, depois os arquivos foram importados no SolidWorks - software de modelagem mecânica - que possui uma ferramenta para análise do arquivo 3D.

Com todas as peças impressas, iniciou-se a fase de acabamento para a pintura com os materiais destacados anteriormente. Tais peças apresentam um acabamento grosseiro, devido ao processo de construção por meio do depósito de camadas. Por isso a massa plástica foi aplicada para se obter uma superfície mais lisa e uniforme.

As lixas devem ser utilizadas na sequência da menor para a maior a partir da sua numeração, pois quanto maior a numeração, mais fina é a lixa. Com o acabamento pronto, foi aplicada a seladora de plástico para que fosse possível iniciar a pintura das peças. 
Figura 9 - Processo de confecção do mockup.

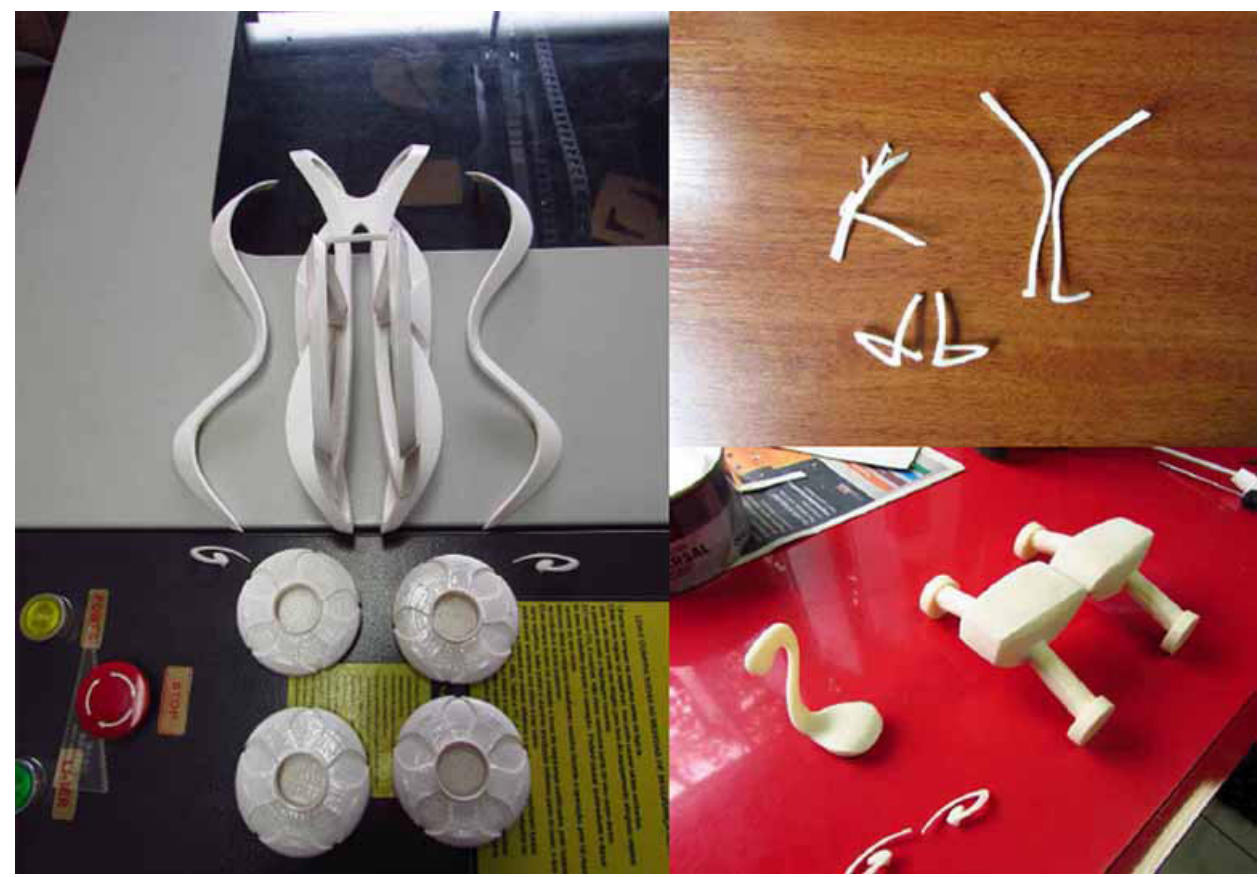

Fonte: Autoria própria.

A colagem foi realizada utilizando cola Epóxi, de modo que o conjunto Cabine + Chassi ficou da seguinte maneira:

Figura 10 - Montagem da Cabine + chassi.

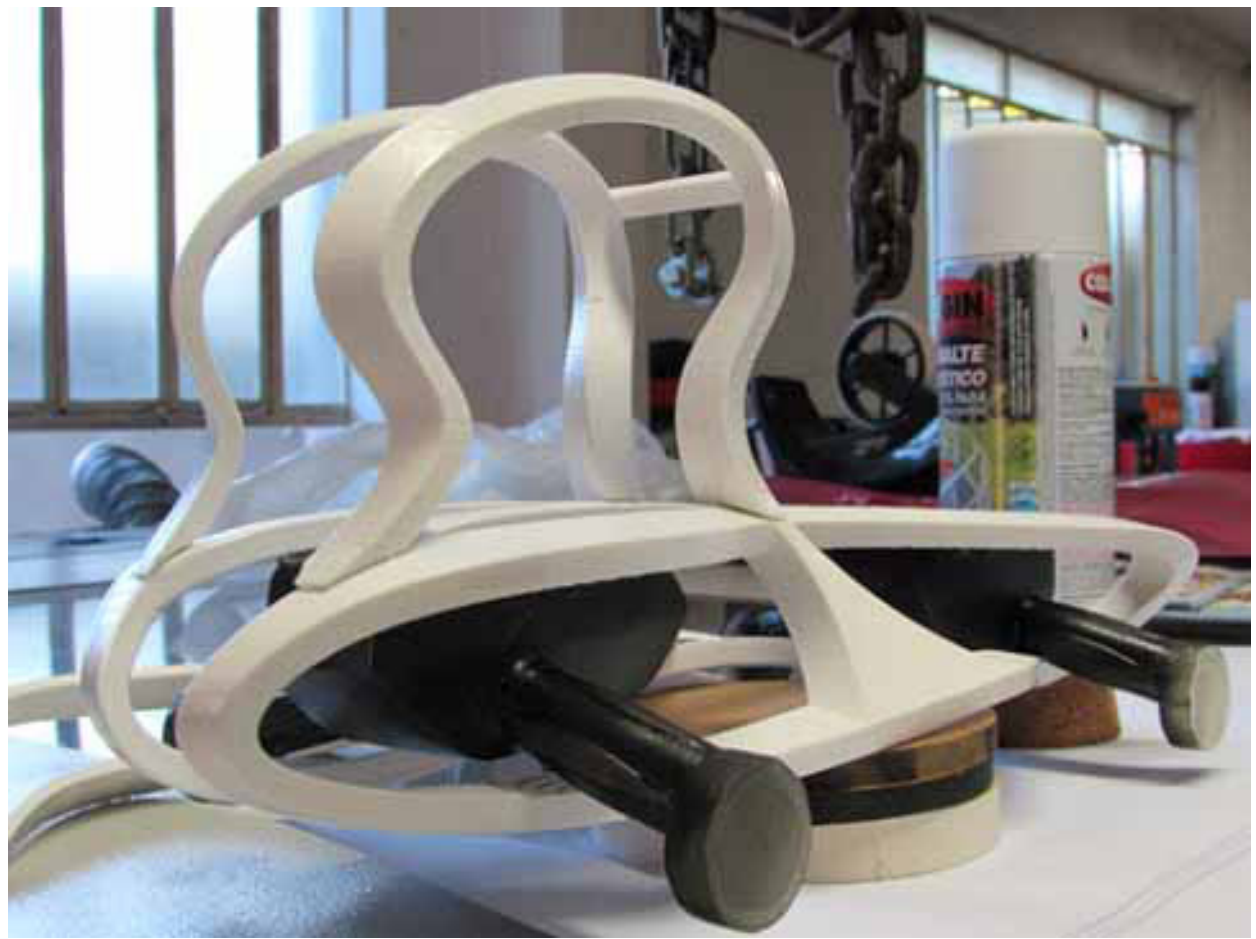

Fonte: Autoria própria. 
Figura 11 - O mockup pronto.

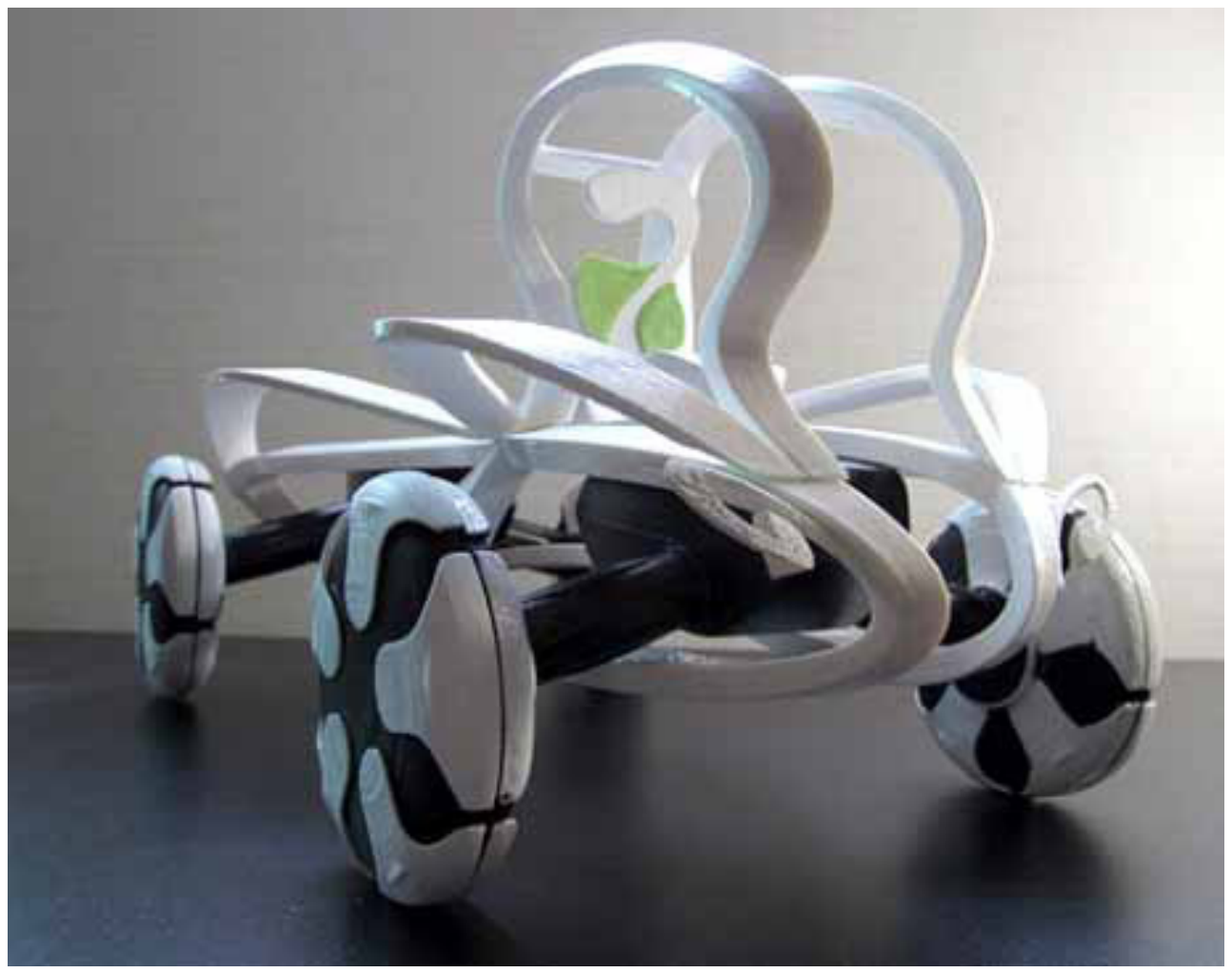

Fonte: Autoria própria.

Figura 12 - O mockup ambientado no gramado.

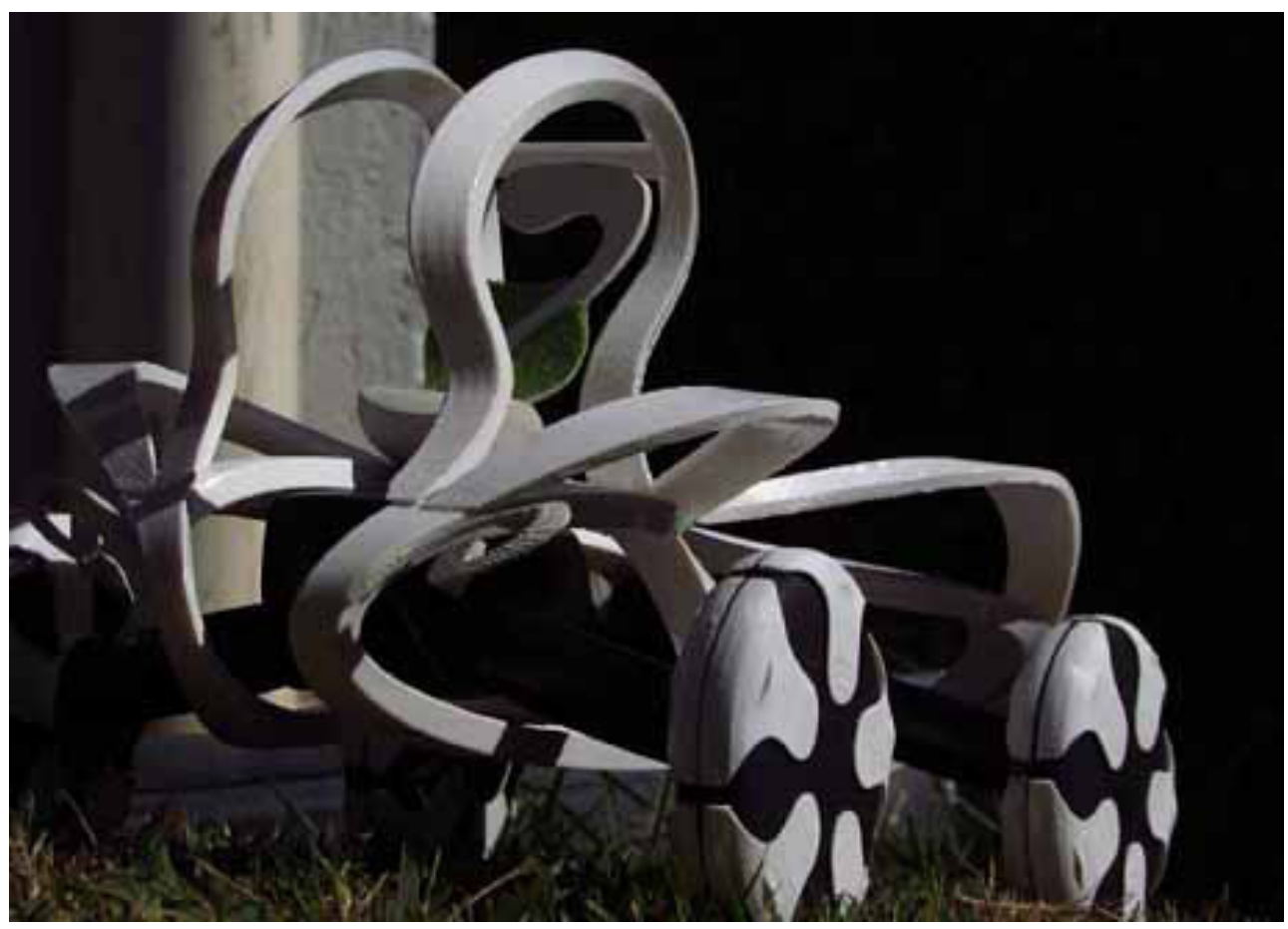

Fonte: Autoria própria.

\section{CONSIDERACÕES FINAIS}

A metodologia aplicada neste projeto foi fundamental para que o objetivo proposto no início fosse atingido. Utilizando este método, foi possível planejar cada etapa do projeto, iniciando da conceituação e ideação, passando pela concepção 
de desenhos manuais e digitais, chegando até a representação de um modelo tridimensional em escala - um mockup.

A alternativa final apresentada trata-se de um projeto de design automotivo conceitual, uma vez que a grande maioria dos materiais, tecnologias e processos de fabricação empregados no projeto não estão facilmente disponíveis para obtenção das indústrias desse segmento assim como não se encontram aplicados nos ambientes agrícolas até o momento. Entretanto, embora os materiais e as técnicas ainda se encontrarem em desenvolvimento é importante a busca de estudos conceituais de novos materiais, mais eficientes e sustentáveis além de formas e linguagens de design que sejam empregadas no desenvolvimento de novos veículos e demais produtos de design.

Vale destacar que o ambiente universitário proporciona a oportunidade de experimentar em busca do acerto, porém, sem o temor do erro, de modo que as investidas errôneas passam a fazer parte do processo de ensinoaprendizagem. Neste sentido, as principais dificuldades encontradas ao realizar este projeto no ambiente universitário foram:

- Pelo fato da cultura do design automotivo não estar totalmente difundida na universidade em que este projeto foi realizado, o processo de concepção do mesmo apresentou um nível de dificuldade maior no que diz respeito: à quantidade de material para o referencial teórico, à disponibilidade de materiais para a utilização na confecção do mockup - tais como Clay e Poliuretano (PU) -, além da escassez de funcionários técnicos com o conhecimento da correta aplicação destes materiais;

- A falta de experiência em modelagem digital por parte do aluno autor do trabalho, o que prejudicou em partes a impressão do volante (o mesmo saiu pouco espesso e consequentemente, extremamente frágil), o que resultou em retrabalho;

- Em dadas fases do projeto, o tempo se mostrou um desafio, justamente pela má gestão do mesmo.

Por fim, este artigo procurou corroborar com a documentação científica, por meio de um relato de experiência, característico de um Trabalho de Conclusão de Curso de Design, que descreveu as teorias e desafios que permeiam a atividade do Design Automotivo. Dessa maneira, espera-se que este texto chegue ao alcance de outros estudantes de Design que desejam desenvolver projetos, estudos e experimentações similares a esta. 


\section{REFERÊNCIAS}

BAXTER, Mike. Projeto de produto: guia prático para o desenvolvimento de novos produtos. 2. ed. São Paulo: E. Blücher, 2001.

CHASE, Richard B.; JACOBS, F. Robert; AQUILANO, Nicholas J. Administração da produção e operações para vantagens competitivas. 11. ed. São Paulo: McGraw-Hill, 2006.

FOOD AND AGRICULTURE ORGANIZATION OF THE UNITED NATIONS. World Food and Agriculture. FAO statistical yearbook 2013. Roma, 2013. Disponível em: <http://www.fao.org/docrep/018/i3107e/i3107e00.htm>. Acesso em: 2 jun. 2015.

GOMES FILHO, João. Gestalt do objeto: sistema de leitura visual da forma. 2. ed. São Paulo: Escrituras, 2006.

LÖBACH, Bernd. Design industrial: bases para a configuração dos produtos industriais. São Paulo: E. Blücher, 2001.

LUPTON, Ellen; PHILLIPS, Ellen Cole. Novos fundamentos do design. São Paulo: Cosac Naify, 2008.

MUNARI, Bruno. Design e comunicação visual. São Paulo: M. Fontes, 1997.

YAMASHITA, Leandro Massayuki Rolim. Mecanização agrícola. Manaus: Instituto Federal do Amazonas, 2010. 